\title{
PENGARUH CARA PENANGANAN TUNA SEGAR PADA SAAT BONGKAR TERHADAP MUTU HASIL TANGKAPAN TUNA LONG LINE DI PPS NIZAM ZACHMAN JAKARTA
}

\author{
Herman Yohanda, Dwi Ernaningsih \\ Fakultas Perikanan dan Ilmu Kelautan \\ Universitas Satya Negara Indonesia, Jakarta
}

\begin{abstract}
ABSTRAK
Penelitian ini bertujuan untuk mengetahui cara penanganan hasil tangkapan ikan tuna segar pada saat bongkar di Pelabuhan Perikanan Samudera Nizam Zachman Jakarta dan melihat hubungan antara cara penanganan ikan tuna di TPT (Tempat Pendaratan Tuna) terhadap mutu hasil tangkapan. Adapun yang menjadi latar belakang penyusunan karya ilmiah ini karena masih banyaknya penanganan hasil tangkapan ikan Tuna segar yang bersifat konvensional atau tidak sesuai dengan standar pada saat bongkar hasil tangkapan, ini menjadi salah satu faktor penurunan kualitas mutu hasil tangkapan. Terkait dengan hal tersebut PPS Nizam Zachman Jakarta telah menerapkan ketentuan Sertifikasi Cara Penanganan Ikan yang Baik pada kapal penangkap ikan dan/atau kapal pengangkut ikan sebagaimana didalam Peraturan Direktur Jenderal Perikanan Tangkap Nomor. 84/PER-DJPT/2013 tentang Sertifikasi Cara Penanganan Ikan Yang Baik (CPIB) pada kapal penangkap ikan dan/atau kapal pengangkut ikan. Melalui ketentuan peraturan tersebut telah dipersyaratkan bahwa kapal penangkap ikan dan/atau pengangkut ikan yang hasil tangkapannya digunakan sebagai bahan baku bagi unit pengolahan ikan untuk tujuan ekspor harus mengikuti tata cara yang sesuai dengan standar selama dalam penanganan sebagai syarat untuk memiliki sertifikat

CPIB. Hasil penelitian ini menunjukan bahwa proses penanganan hasil tangkapan Tuna Long Line di PPS Nizam Zachman Jakarta dilakukan dengan beberapa tahapan: pembongkaran, pemindahan ke transit, penyeleksian berdasarkan grade, pencucian dan pembersihan sisa isi perut serta bagian insang, penimbangan, pencatatan dan pemberian tanda/label, penyimpanan dalam bak sementara dan pengemasan. Terdapat hubungan yang linier antara cara penanganan ikan tuna dengan peningkatan dan penurunan mutu hasil tangkapan di TPT/TLC.
\end{abstract}




\section{Kata Kunci: TPT (Tempat Pendaratan Tuna), CPIB (Cara Penanganan Ikan Yang Baik), Tuna Longline, PPS (Pelabuhan Perikanan Samudera), mutu hasil tangkapan}

\section{PENDAHULUAN}

Sulitnya kapal Long Line mendapatkan tuna, dengan dilihat dari semakin jauhnya jarak tempuh dan lamanya waktu melaut, maka menjaga kualitas mutu pada setiap tahap penanganan hasil tangkapan menjadi sebuah keharusan. Diharapkan dengan demikian perikanan tuna tetap eksis dan dapat bersaing dalam bisnis perikanan tangkap yang semakin kompetitif.

Peran serta pelaku usaha dan pemerintah sangat diperlukan dalam menjamin produk perikanan hasil tangkapan yang memiliki standar mutu baik. Pelaku usaha berperan untuk menangani ikan hasil tangkapannya sebaik mungkin atau sesuai dengan SNI 01-2710.3-2006 tentang penanganan dan pengolahan tuna segar. Masih banyaknya penanganan yang bersifat konvensional atau tidak sesuai dengan standar pada saat bongkar hasil tangkapan, menjadi salah satu faktor penurunan kualitas mutu.

Tujuan penelitian ini untuk mengetahui cara penanganan ikan tuna segara pada saat bongkar dan mengkaji hubungan anatara cara penanganan ikan tuna segar di TPT (Tempat Pendaratan Tuna) terhadap mutu hasil tangkapan.

Penelitian ini dilakukan di Pelabuhan Perikanan Samudera Nizam Zachman Jakarta pada bulan 14 Mei sampai 31 Juli 2016.Pemilihan lokasi penelitian di PPSNZ Jakarta didasarkan pada kondisi perikanan tuna yang semakin menurun secara kuantitas. Awalnya di PPSNZ Jakarta terdapat 29 TPT. Kini hanya tersisa 4 TPT (TPT 2; TPT 16; TPT 17; TPT 18) yang masih bertahan melakukan aktivitas bongkar tuna fresh.

\section{METODE PENELITIAN}

Penelitian ini dilakukan dengan menggunakan metode penelitian studi kasus. Peneliti melakukan pengamatan langsung terhadap cara penanganan tuna yang didaratkan di masingmasing TPT, melakukan penilaian (skoring) terhadap 4 TPT yang menjadi lokasi penelitian, serta melakukan wawancara kepada ABK, nakhoda kapal dan checker.

Analisis data dilakukan secara deskriptif dan kuantitatif melalui penyajian dalam bentuk tabel dan grafik serta analisis terhadap penentuan mutu daging ikan. Kajian proses penanganan tuna di TLC/TPT pada saat bongkar dilakukan untuk melihat hubungan antara penanganan ikan 
tuna dengan kualitas mutu yang dihasilkan dari masing-masing TLC/TPT.Data yang terkumpul diolah menggunakan regresi linier (Ronald, E. Walpole, 1992) = +

$\mathrm{a}=(\Sigma \mathrm{Y})(\Sigma \mathrm{X} 2) 2-(\Sigma \mathrm{X})(\Sigma 2 \mathrm{XY})(\mathrm{n})(\Sigma \mathrm{X})-(\Sigma \mathrm{X})$

$\mathrm{b}=(\mathrm{n})(\Sigma \mathrm{XY}) 2-(\Sigma \mathrm{X})(\Sigma 2 \mathrm{Y})(\mathrm{n})(\Sigma \mathrm{X})-(\Sigma \mathrm{X})$

\section{Dimana :}

$\mathrm{Y}=$ Prosentase Mutu Hasil Tangkapan

$\mathrm{X}=$ Nilai Skoring TPT $\mathrm{a}=$ konstanta

$\mathrm{b}=$ koefisien regresi

r2= koefisien determinasi

$\mathrm{r}=$ Nilai hubungan antara variabel bebas mutu hasil tangkapan $(\mathrm{X})$ dengan variabel tak bebas nilai skoring TPT (Y)

$\mathrm{R} 2=(\mathrm{n}(\Sigma \mathrm{X} 2)-(\Sigma \mathrm{X}) 2(\mathrm{n}(\Sigma \mathrm{Y} 2)-(\Sigma \mathrm{Y}) 2)$

Selanjutnya melakukan pengujian hipotesis dimana H0 : Ada hubungan antara cara penanganan hasil tangkapan sesuai standar dengan mutu hasil tangkapan, dan H1 : Tidak ada hubungan antara cara penanganan hasil tangkapan sesuai standar dengan mutu hasil tangkapan, pada selang kepercayaan $95 \%$.

\section{PEMBAHASAN}

Tahapan Proses Kerja Pada Penanganan Tuna Segar Penanganan tuna segar dari proses pembongkaran/pendaratan sampai pada pengemasan dapat dilihat sebagai berikut :

\section{Pembongkaran/Pendaratan tuna}

Proses pembongkaran tuna fresh dilakukan pada pagi sampai dengan siang hari sekitar jam 07.30 WIB sampai dengan 12.00 WIB. Suhu palkah pada kondisi dibawahPenutup $5^{\circ} \mathrm{C}$ seperti. tenda di pasang dari kapal ke tempat pendaratan tuna (TPT) untuk menghindari tuna terpapar oleh sinar matahari pada saat pemindahan, karena sinar matahari dapat menaikan histamine pada 
tuna.Tuna didaratkan dalam bentuk utuh yang sudah disiangi isi perut dan insangnya dengan maksimal suhu ikan adalah 20C.

2. Pemindahan ke Transit

Ikan yang sudah diangkat dari dalam palkah kapal kemudian diangkat satu persatu kepapan peluncur untuk masuk kedalam ruangan transit.

\section{Pemotongan sirip}

Pemotongan sirip dilakukan untuk

menghindari kemunduran mutu, kontaminasi bakteri patogen, dan kemudahan dalam proses pengemasan.

4. Sortasi mutu ikan

Sortasi mutu dilakukan oleh checker

untuk memeriksa kualitas daging tuna yang memenuhi persyaratan kualitas ekspor dengan menggunakan alat coring tube yang ditusukan pada bagian belakang sirip pectoral dan pangkal ekor sehingga diperoleh potongan daging sebagai bahan penilaian/penentuan grade ikan.

\section{Pencucian}

Pencucian dilakukan kembali untuk

memastikan kotoran dan kontaminasi bakteri telah hilang. Pencucian dilakukan dengan cara mengusap pada bagian tubuh ikandengan air dingin.

6. Penimbangan, Pencatatan dan Penandaan

Ikan yang telah dibersihkan kemudian

ditimbang untuk mengetahui berat ikan dan dicatat kedalam tally sheet, .setelah itu dilakukan penandaan dengan tujuan untuk membedakan yang akan menjadi tujuan ekspor atau local Hubungan Penanganan Tuna Segar Pada Saat Bongkar Dengan Mutu Hasil Tangkapan

Hasil penanganan menunjukan bahwa mutu ikan diklasifikasikan kedalam empat kategori yaitu ; mutu 1, mutu 2, mutu 3, dan mutu 4. Produksi hasil tangkapan ikan tuna yang didaratkan di masing-masing TPT berdasarkan identifikasi mutu.

Tabel 1. Jumlah Produksi Yellowfin Tuna dan Bigeye Tuna per TPT 


\begin{tabular}{cccccccccc}
\hline \multicolumn{10}{c}{ Produksi Tuna Berdasarkan Mutu (Kg) } \\
\hline \multirow{2}{*}{ TPT/TLC } & \multicolumn{1}{c}{ Mutu 1 } & \multicolumn{2}{c}{ Mutu 2 } & \multicolumn{2}{c}{ Mutu 3 } & \multicolumn{2}{c}{ Mutu 4 } & \multirow{2}{*}{ Total } \\
\cline { 2 - 9 } & Yft & Bet & Yft & Bet & Yft & Bet & Yft & Bet & \\
\hline 2 & 638 & 2588 & 399 & 1413 & 822 & 1889 & 146 & 1490 & 9386 \\
16 & 5944 & 26006 & 2716 & 4142 & 619 & 2286 & 780 & 2797 & 45289 \\
17 & 17914 & 18805 & 11745 & 6494 & 9917 & 6633 & 724 & 3312 & 75544 \\
18 & 12175 & 21669 & 542 & 5915 & 642 & 10755 & 197 & 2958 & 54854 \\
\hline Jumlah & 36671 & 69069 & 15402 & 17964 & 11999 & 21564 & 1847 & 10557 & 185073 \\
\hline
\end{tabular}

Keterangan: Yft = Yellowfin Tuna; Bet = Bigeye Tuna (IOTC, FAO Code)

Jumlah produksi yang ditampilkan pada Tabel.1 menunjukan keragaman untuk masingmasing TPT/TLC. Hal ini disebabkan karena jumlah produksi hasil tangkapan masing-masing TPT/TLC tidak sama. Tiap TPT/TLC memiliki jumlah armada yang berbeda baik jumlah maupun ukuran GT kapal.

Keragaman jenis hasil tangkapan yang dominasi oleh Big Eye Tuna terkait dengan desain alat tangkap Long Line yang digunakan oleh masing-masing armada penangkapan. Big Eye Tuna hidup pada kolom perairan yang lebih dalam dari Yellowfin Tuna. Desain alat tangkap Long Line dengan Branch Line yang lebih dalam, berpeluang menangkap ikan jenis Big Eye Tuna lebih besar. Sementara jika Branch Line dangkal, peluang mendapatkan ikan jenis Yellowfin Tuna yang lebih besar.

Perbedaan jumlah produksi yang tersaji dalam Tabel 1. akan menjadi bias bila diperbandingkan untuk melihat kualitas penanganan di masing-masing TPT/TLC. Langkah untuk mendapatkan informasi yang objektif dengan merubah jumlah produksi yang sebelumnya tersaji dalam satuan kilogram, dirubah dalam bentuk prosentase. Jumlah total produksi dalam kilogram yang beragam disemua TPT/TLC, diasumsikan bahwa semua data tersebut berjumlah 100\% untuk masing-masing TPT/TLC. Selanjutnya angka produksi untuk tiap mutu dan spesies dirubah dalam bentuk prosentase, hasilnya tersaji dalam Tabel 2 dengan demikian maka sudah dapat dilakukan pembandingan kualitas penanganan masing-masing TPT/TLC tanpa harus ada bias karena perbedaan jumlah produksi dalam kilogram.

Tabel 2. Prosentase Produksi Yellowfin Tuna dan Bigeye Tuna per TPT

Prosentase Produksi Tuna Berdasarkan Mutu (\%) 


\begin{tabular}{ccccccccccc}
\hline & Mutu 1 & \multicolumn{3}{c}{ Mutu 2 } & \multicolumn{5}{c}{ Mutu 3 } & \multicolumn{3}{c}{ Mutu 4 } \\
\cline { 2 - 10 } TPT/TLC & & & & & & & & \\
& Yft & Bet & Yft & Bet & Yft & Bet & Yft & Bet \\
& & & & & & & & \\
\hline 2 & 6,8 & 27,6 & 4,3 & 15,1 & 8,8 & 20,1 & 1,6 & 15,9 \\
16 & 13,1 & 57,4 & 6,0 & 9,1 & 1,4 & 5,0 & 1,7 & 6,2 \\
17 & 23,7 & 24,9 & 15,5 & 8,6 & 13,1 & 8,8 & 1,0 & 4,4 \\
8 & 22,2 & 39,5 & 1,0 & 10,8 & 1,2 & 19,6 & 0,4 & 5,4 \\
\hline
\end{tabular}

Nilai skoring penanganan hasil tangkapan masing-masing TPT adalah : TPT $2=196$; TPT $16=$ 238; TPT $17=224$; TPT $18=250$. Hubungan antara nilai skoring transit dengan naik turunnya mutu ikan tuna pada spesies Big Eye Tuna (Bet) dan Yellowfin Tuna (Yft) tersaji sebagai berikut:

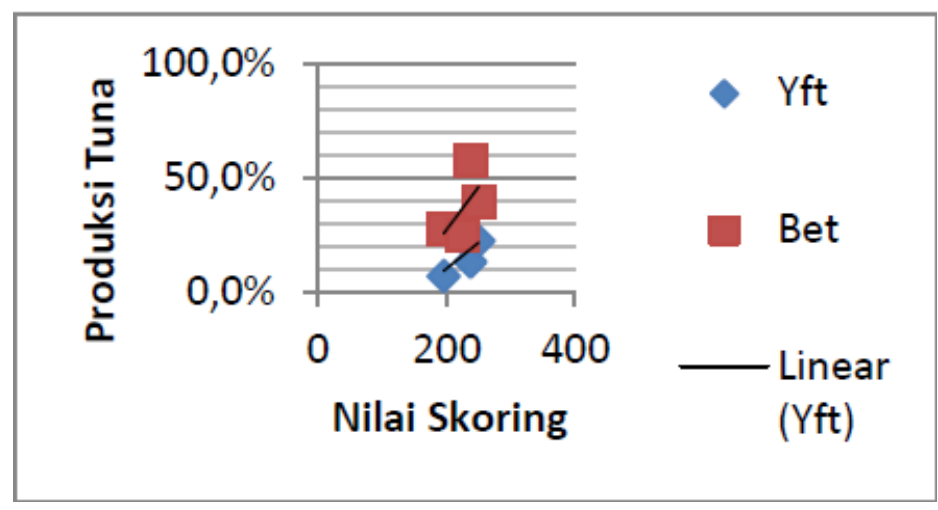

Gambar 1. Hubungan nilai skoring dengan produksi mutu 1

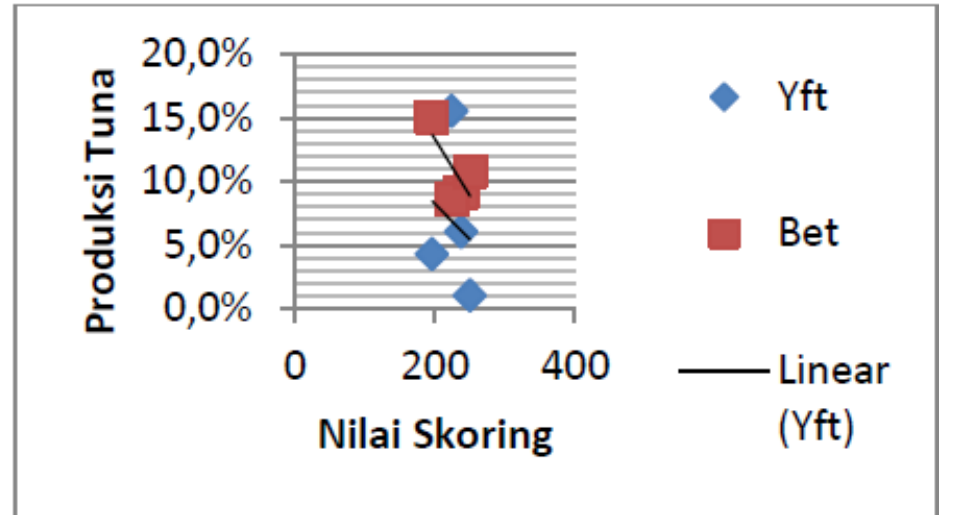


Gambar 2. Hubungan nilai skoring dengan produksi mutu 2

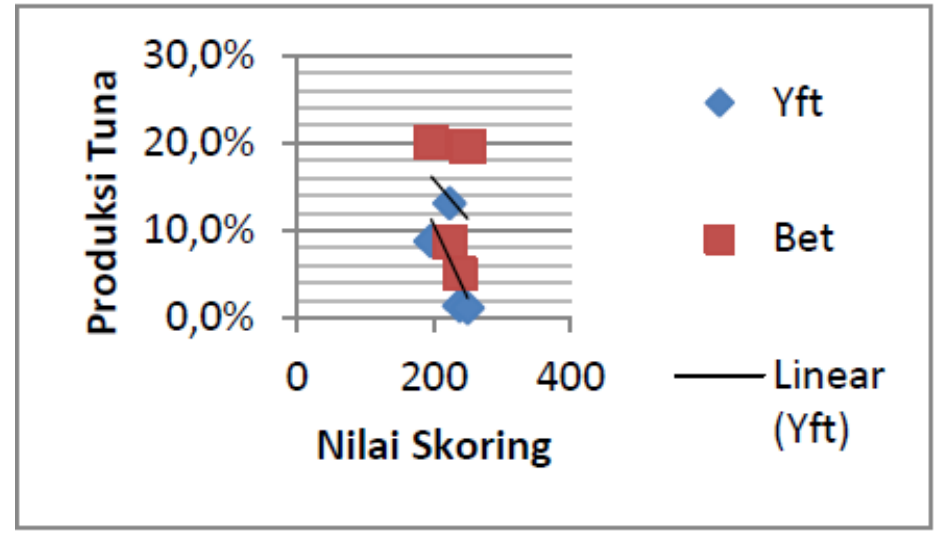

Gambar 3. Hubungan nilai skoring dengan produksi mutu 3

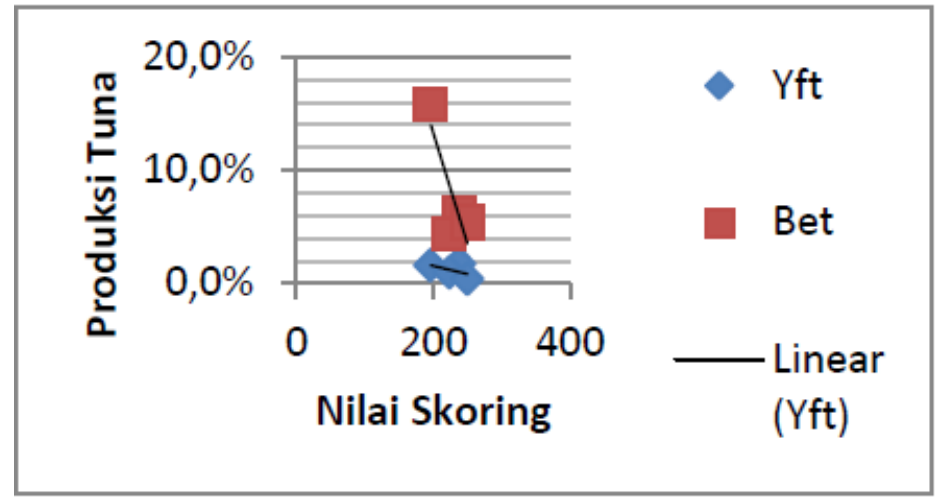

Gambar 4. Hubungan nilai skoring dengan produksi mutu 4

Pada Gambar 1 trend tuna mutu 1 terlihat bahwa semakin tinggi nilai skoring suatu TPT/TLC maka persentase grade mutu 1 nya pun akan meningkat. Sementara pada Gambar 2, 3, dan 4 untuk mutu 2, 3, dan 4 terlihat trend sebaliknya. Semakin menurun nilai skoring TPT/TLC menyebabkan peningkatan pada jumlah persen ikan tuna bermutu 2, 3, dan 4. Hal tersebut berlaku sama untuk Bigeye Tuna dan Yellowfin Tuna. Hubungan antara nilai skoring TPT/TLC dengan jumlah persentase naik turunnya mutu ikan yang menjadi produksi tersaji dalam persamaan hubungan Y dan X.

Tabel 3. Nilai Hubungan antara Mutu Hasil Tangkapan dengan Nilai Skoring.

\begin{tabular}{lllllll} 
Mutu Bet & Yft & $\mathbf{r}^{2}$ Bet & r Bet & $\mathbf{r}^{2}$ Yft & r Yft \\
\hline $\mathbf{1} \quad \mathrm{y}=0,0023 \mathrm{x}-0,3583$ & $\mathrm{y}=0,0038 \mathrm{x}-0,4822$ & 0,3497 & 0,5914 & 0,4521 & 0,6724
\end{tabular}




$$
\begin{array}{lllllll}
\mathbf{2} & \mathrm{y}=-0,0006 \mathrm{x}+0,1929 \mathrm{y}=-0,0009 \mathrm{x}+0,3107 & 0,0425 & 0,2062 & 0,4980 & 0,7057 \\
\mathbf{3} & \mathrm{y}=-0,0009 \mathrm{x}+0,3356 \mathrm{y}=-0,0017 \mathrm{x}+0,4378 & 0,0731 & 0,2704 & 0,4326 & 0,6577 \\
\mathbf{4} & \mathrm{y}=-0,0019 \mathrm{x}+0,5186 \mathrm{y}=-0,0001 \mathrm{x}+0,0449 & 0,7111 & 0,8433 & 0,3049 & 0,5522
\end{array}
$$

Pengaruh paling signifikan terjadi pada Bigeye Tuna mutu 4 dengan nilai $\mathrm{r}$ sebesar 0.8433, artinya cara penanganan tuna di TPT/TLC sangat mempengaruhi agar Bigeye Tuna tidak turun pada level mutu terendah. Sementara pengaruh terkecil terjadi pada Bigeye Tuna mutu 2 dengan nilai $r$ sebesar 0.2062. Pada hasil tangkapan Yellowfin Tuna nilai r tidak menunjukan fluktuatif yang signifikan. Nilai $r$ terendah sebesar 0.5522 dimiliki Yellowfin Tuna mutu 4, sedangkan yang tertinggi dimiliki Yellowfin Tuna mutu 2 dengan nilai 0.7057.

Tuna Landing Centre dengan nilai skoring tertinggi 250 memiliki produksi ikan mutu 4 terendah namun produksi ikan mutu 1 nya ada pada urutan ke 2, ini dimiliki oleh TPT/TLC 18. Produksi ikan mutu 1 tertinggi ada pada TPT/TLC 16 dengan nilai skoring 238, TPT/TLC dengan nilai skoring terendah 196 memiliki produksi ikan mutu 1 paling rendah dan mutu 4 paling tinggi, ini dimiliki oleh TPT/TLC 2. Nilai r tertinggi untuk Bigeye Tuna ada pada mutu 4 sebesar 0,8433 dan Yellowfin Tuna ada pada mutu 2 sebesar 0,7057. Hal ini terjadi karena kemampuan adaptasi ikan Bigeye Tuna dan Yellowfin Tuna berbeda terhadap kondisi pasca penangkapan. Sesaat setelah ditangkap ikan akan mati bahkan ada yang mati sebelum naik ke kapal. Pada tahap awal kematian ikan memasuki fase Prerigor. Bigeye Tuna memiliki habitat di wilayah termoklin lebih lama mengalami proses penurunan mutu dibanding Yellowfin Tuna yang memiliki habitat diatas termoklin (epilimnion).

Yellowfin Tuna memiliki nilai $\mathrm{r}$ tinggi pada kondisi mutu 2 karena pengaruh mikro organisme bawaan dari wilayah epilimnion yang lebih banyak dibanding termoklin. Aktifitas mikro organisme bawaan ditambah kontaminasi dari TPT/TLC akan mempercepat laju penurunan mutu Yellowfin Tuna di awal, inilah yang menyebabkan nilai r nya tinggi pada mutu 2. Sementara Bigeye Tuna penurunan mutunya merupakan akumulasi dari rantai penanganan di TPT/TLC sehingga pengaruh penurunan mutu paling besar terjadi pada mutu 4 dengan nilai $\mathrm{r}$ paling besar.

Produksi ikan mutu 1 tertinggi dimiliki TPT/TLC 16 padahal nilai skoringnya urutan kedua sebesar 238. Hal ini diasumsikan karena pengaruh dari cara penanganan ikan diatas kapal lebih dominan dalam menentukan jumlah prosentase mutu 1 hasil tangkapan dalam armada tuna 
longline. Dalam rangkaian penanganan hasil tangkapan di TPT/TLC, ikan dengan mutu 1 sesaat setelah penyeleksian grade akan langsung dilakukan pencucian dan pembersihan sisa isi perut serta bagian insang, penimbangan, pencatatan, pemberian tanda/label, penyimpanan sementara dalam bak es dan pengemasan, kemudian ikan dikirim ke bandara untuk export fresh. Ikan dengan mutu 2, 3, dan 4 setelah penyeleksian grade ikan akan dibiarkan tergeletak di lantai sambil menunggu pembeli datang. Pembeli kembali melakukan penyeleksian grade berdasarkan standar perusahaan masing-masing. Ikan kemudian diangkut ke perusahaan dengan kondisi mutu sudah menurun karena rantai dingin yang tidak terjaga, kontaminasi dari lantai dan air yang tidak steril.

Tahap selanjutnya adalah melakukan pengujian hipotesis, berikut hasil uji hipotesis.

\begin{tabular}{|c|c|c|l|}
\hline Bet / & & t tabel & Keputusan \\
Yft & & & \\
\hline Bet 1 & 1,037048 & 3,182446 & Terima H0 \\
\hline Yft 1 & 1,284745 & 3,182446 & Terima H0 \\
\hline Bet 2 & $-1,40861$ & 3,182446 & Terima H0 \\
\hline Yft 2 & $-0,29783$ & 3,182446 & Terima H0 \\
& & & \\
\hline Bet 3 & $-0,39709$ & 3,182446 & Terima H0 \\
\hline Yft 3 & $-1,23494$ & 3,182446 & Terima H0 \\
\hline Bet 4 & $-2,21896$ & 3,182446 & Terima H0 \\
\hline & & & \\
\hline & & & \\
\hline & & & \\
\hline & & & \\
\hline & & & \\
\hline & & & \\
\hline & & & \\
\hline & & & \\
\hline
\end{tabular}


Hasil yang sama diperoleh untuk semua pengujian yakni terima H0. Artinya ada hubungan antara peningkatan mutu dengan cara penanganan ikan tuna di TPT. Semakin baik cara penanganan ikan tuna yang dilakukan masing-masing TPT maka akan berkorelasi positif dengan jumlah ikan tuna kualitas mutu 1 dan berkorelasi negatif denganjumlah ikan tuna mutu 2, 3, dan 4 yang diproduksi TPT/TLC tersebut.

\section{KESIMPULAN}

1. Proses penanganan hasil tangkapan tuna longline di PPS Nizam Zachman Jakarta diawali pembongkaran dari kapal, pemindahan ke transit, penyeleksian berdasarkan grade, pencucian dan pembersihan sisa isi perut serta bagian insang, penimbangan, pencatatan dan pemberian tanda/label, penyimpanan dalam bak sementara dan pengemasan.

2. Terdapat hubungan yang linier antara cara penanganan ikan tuna dengan peningkatan dan penurunan mutu hasil tangkapan di TPT/TLC. Semakin tinggi nilai skoring TPT/TLC maka prosentase hasil tangkapan mutu 1 yang dihasilkan meningkat, sedangkan mutu 2, 3, dan 4, menurun.

\section{DAFTAR PUSTAKA}

Afrianto, E dan Liviawaty, E., 2002. Pengawetan dan Pengolahan Ikan. Yogyakarta : Kanisius Ayodhya, A. U. 1981. Teknik Penangkapan Ikan. Penerbitan Yayasan Dewi Sri. Bogor. Fadly, N. 2009. Asesmen Risiko Histamin Ikan Tuna (Thunnus sp.) Segar Berbagai Mutu Ekspor Pada proses Pembongkaran (Transit) Skripsi. Bogor: Program Studi Teknologi Hasil Perikanan, Fakultas Perikanan dan Ilmu Kelautan, Institut Pertanian Bogor.

Gomez, Kwanchai \& Arturo A. Gomez.1995. Prosedur Statistik Untuk Penelitian Pertanian (Edisi Kedua). Penerbit Universitas Indonesia, Jakarta.

Junianto, 2003 Teknik Penanganan Ikan, Penebar Swadaya, Jakarta

Keputusan Menteri Kelautan dan Perikanan Nomor. KEP.60/MEN/2001 tentang Penataan Penggunaan Kapal Perikanan di Zona Ekonomi Eksklusif Indonesia (Dirjen Perikanan Tangkap, 2005)

Mahendra. N, Timor. 2005. Evaluasi Resiko Bahaya Keamanan Pangan (HACCP) tuna kaleng dengan metode statistical process. (skripsi), Program Studi Teknologi Hasil Perikanan, Fakultas Perikanan Institut Pertanian Bogor, Bogor.

Ronald, E. Walpole, Pengantar Statistika, PT. Gramedia Pustaka Utama, Jakarta, ke-3, 1992.

Suryawan, A. G. 2004. Karakteristik perubahan mutu ikan selama penanganan oleh nelayan tradisional dengan jaring rampus (studi kasus di Kaliadem, Muara Angke, DKI Jakarta. Skripsi. Departemen Teknologi Hasil Perikanan. Fakultas Perikanan dan Ilmu Kelautan. Institut Pertanian Bogor. Bogor

Tim Penyusun Laporan pelaksanaan sertifikasi CPIB, 2014 Petunjuk Teknis Cara Penanganan 
Ikan yang Baik

Wibowo, S. dan Yunizal, 1998. Penanganan ikan segar. Instalasi Perikanan Laut Slipi. Jakarta 